www.jmscr.igmpublication.org

Impact Factor (SJIF): 6.379

Index Copernicus Value: 79.54

ISSN (e)-2347-176x ISSN (p) 2455-0450

crossrefDOI: https://dx.doi.org/10.18535/jmscr/v6i11.70

Journal Of Medical Science And Clinical Research

IGM Publication

An Official Publication of IGM Publication

\title{
Profile of benign breast disease in Uttarakhand
}

Authors

Dr Dinesh Singh Chauhan ${ }^{1 *}$, Dr Navneet Jain ${ }^{2}$

${ }^{1}$ Senior Resident, Dept. of General Surgery, GDMC Dehradun, Uttarakhand

${ }^{2}$ Associate Professor, Dept. of General Surgery, GDMC Dehradun, Uttarakhand

*Corresponding Author

Dr Dinesh Singh Chauhan

Address: Government Doon Medical College and Hospital Dehradun Uttarakhand Pin 248006, India

Email:drdinesh0225@gmail.com

\begin{abstract}
Background: Benign breast lesions are the most common breast disease in females. This study was conducted to study the clinical profile and pattern of benign breast disease and its pathological correlation.

Methods: One hundred five females who attended the Surgery Outpatients Department in Government Doon Medical College, Dehradun, with various forms of benign breast diseases during the period from October 2017 to September 2018, were studied. Early diagnoses by doing a triple assessment like a clinical examination, FNAC or a core needle biopsy and imaging methods like ultrasonography or mammography, were made within 72 hrs from the first consultation. The clinical diagnoses were compared with final diagnosis.
\end{abstract}

Results: Out of the 105 female patients who were studied, $46.66 \%$ patients were in the age group of 21 to 30 years. $63.80 \%$ patients presented with breast lumps and fibroadenoma, accounted for $46.66 \%$ of the cases, which was the highest number of patients. Fibrocystic changes and breast abscesses came next with $29.52 \%$ and $6.66 \%$ cases respectively. The right breast was involved in 45 (42.85\%) patients, and upper outer quadrant was most commonly involved (59.04\%).

Conclusion: Results grossly similar to other parts of the word were obtained. Benign breast diseases are common in female patients in the second followed by third decade of their life. Breast lump is the most common presentation involving the upper outer quadrant and of all the benign breast diseases fibroadenoma is the commonest of them all. Triple assessment provided a quick diagnosis and it alleviated unnecessary anxiety from the patients about breast cancer. Breast self-examination and education to the females is required for early diagnosis and prompt treatment as majority of anxiety and worry of having breast cancer can be alleviated.

Keywords: Benign breast disease, Fibroadenoma, Fibroadenosis, Triple assessment.

\section{Introduction}

The breast has always been the symbol of womanhood and ultimate fertility. As result both, disease and surgery of the breast evoke a fear of mutilation \& loss of femininity. Benign breast diseases account for about $80 \%$ of the breast pathology. Very few benign breast diseases have an ability to become malignant, but the majority 
are treated easily without adverse consequences. However, management of some benign breast diseases proven to be troublesome and associated with high psychological morbidity. A triple assessment which is done by a clinical examination imaging like ultrasonography (USG) or mammography and a pathological examination - FNAC or core needle biopsy, during the initial consultation, allows a majority of the patients with discrete BBDs to be given immediate reassurance. Mammography, often in conjunction with ultrasound examination ${ }^{[1],[2], ~[3], ~[4] ~}$ is required for evaluation of discrete palpable lesions in women over 35 whereas ultrasound provides an optional substitute in younger women ${ }^{[5]}$. Round dense lesions on mammography often represent cysts which require only ultrasonography to distinguish them from solid lesions. Complex cysts containing both fluid and solid matter require biopsy. For solid lesions, radiographically or ultrasonically directed core biopsy provides highly discriminative information regarding the presence or absence of malignancy. Pathologically, BBD is divided into nonproliferative disease, proliferative disease without atypia, and proliferative disease with atypia. ${ }^{[6],[7][8]}$. The risk of breast cancer is higher in proliferative disease, especially atypical proliferative lesions. ${ }^{[6],[9]}$

In this study, we profiled the incidence of BBDs, the relative frequencies of the different types of BBDs and their clinical features. Secondly, we attempted at correlating the clinical and pathological findings wherever possible.

\section{Materials and Methods}

This study was conducted in Government Doon Medical College, Dehradun, Uttarakhand (Devbhoomi), India located at the foothills of the Himalayan mountain ranges, and it is largely a hilly State. The study was conducted for one year period from October 2017 to September 2018. Informed consent was taken from the patients under study. Females of all age group with any complaint relating to breast were included in the study. Women with an obvious malignant disease or those who had been treated for malignancy earlier, were excluded in this study. After a detailed history and a thorough physical examination one or more of the special investigations- FNAC, mammography, ultrasound or a core-needle biopsy were carried out for the confirmation of the diagnosis. Surgery was done when indicated and the specimen was subjected to histopathological examination.

\section{Results}

\section{Age distribution}

The present study group comprised of 105 female patients with benign breast disease. Benign breast disease was commonly seen in the age group of 21-30years constituting $46.66 \%$ of all patients followed by $23.80 \%$ cases in age group of 31 40years. The age distribution pattern of benign breast disease is depicted in Table 1.

Table 1 Age distribution pattern of benign breast disease

\begin{tabular}{|cc|c|c|}
\hline Age in years & $\begin{array}{c}\text { No. of } \\
\text { patients }\end{array}$ & Percentage \\
\hline 1. & $11-20$ & 11 & 10.47 \\
\hline 2. & $21-30$ & 49 & 46.66 \\
\hline 3. & $31-40$ & 25 & 23.80 \\
\hline 4. & $41-50$ & 13 & 12.38 \\
\hline 5. & $51-60$ & 7 & 6.66 \\
\hline \multicolumn{2}{r}{ Total } & 105 & \\
\hline
\end{tabular}

\section{Clinical presentation}

The most common clinical presentation was lump in the breast.67 patients $(63.80 \%)$ presented with lump in the breast without any other complaint followed by 14 patients (13.33\%) who complained of a lump with associated pain. The type of presentation is depicted in Table 2.

Table 2 Type of presentation with incidence

\begin{tabular}{|cl|c|c|}
\hline \multicolumn{1}{|c|}{ Presentation } & $\begin{array}{c}\text { No. of } \\
\text { patients }\end{array}$ & Percentage \\
\hline 1. & Breast lump only & 67 & 63.80 \\
\hline 2. & Breast lump +pain & 14 & 13.33 \\
\hline 3. & $\begin{array}{l}\text { Breast lump +nipple } \\
\text { discharge }\end{array}$ & 7 & 6.66 \\
\hline 4. & Breast pain only & 11 & 10.47 \\
\hline 5. & $\begin{array}{l}\text { Nipple discharge } \\
\text { only }\end{array}$ & 6 & 5.71 \\
\hline \multicolumn{2}{|c|}{ Total } & 105 & \\
\hline
\end{tabular}




\section{Distribution pattern of benign breast disease}

The most common benign lesion was fibroadenoma constituting $46.66 \%$ of the cases followed by fibroadenosis $29.52 \%$ cases. The other benign lesions in the study group were breast abscess (6.66\%), duct ectasia (4.76\%), mastitis (4.76\%), galactocoele $(4.76 \%)$, simple cyst $(1.90 \%)$ and sinus $(0.95 \%)$ depicted in Table 3.

Table 3 Distribution pattern of benign breast disease

\begin{tabular}{|l|c|c|}
\hline $\begin{array}{l}\text { Benign Breast } \\
\text { Disease }\end{array}$ & $\begin{array}{c}\text { No. of } \\
\text { patients }\end{array}$ & $\begin{array}{c}\text { Incidence } \\
\text { percentage }\end{array}$ \\
\hline Fibroadenoma & 49 & 46.66 \\
\hline Fibroadenosis & 31 & 29.52 \\
\hline Breast abscess & 7 & 6.66 \\
\hline Duct ectasia & 5 & 4.76 \\
\hline Mastitis & 5 & 4.76 \\
\hline Galactocoele & 5 & 4.76 \\
\hline Simle cyst & 2 & 1.90 \\
\hline Sinus & 1 & 0.95 \\
\hline
\end{tabular}

\section{Side wise and quadrant wise distribution}

Among the 105 patients, the right breast was affected in $45(42.85 \%)$ patients, while the left breast was affected in $40(38.09 \%)$ patients. In 20 $(19.04 \%)$ cases, both the breasts were affected, as shown in table 4 . Most benign lesions were found in the upper outer quadrant $59.04 \%$ followed by central quadrant $14.28 \%$ as shown in Table 4.

Table 4 Side and quadrant wise distribution of benign breast disease

\begin{tabular}{|l|c|c|}
\hline Side Involved & No. of cases & Percentage \\
\hline Right breast & 45 & 42.85 \\
\hline Left breast & 40 & 38.09 \\
\hline Both breast & 20 & 19.04 \\
\hline Quadrant involved & & \\
\hline UOQ & 62 & 59.04 \\
\hline UIQ & 15 & 14.28 \\
\hline LOQ & 10 & 9.52 \\
\hline LIQ & 04 & 3.80 \\
\hline Central quadrant & 19 & 18.09 \\
\hline
\end{tabular}

\section{Investigations}

Out of 105 patients FNAC was done in 80 patients and the results were confirmed to be similar to the histopathologic examinations in 66 cases. Ultrasound was done in 25 patients where FNAC results were inconclusive and in patients with non palpable lesions. Mammography was done in only 8 patients. Core needle biopsy was done in patients where all the investigations were inconclusive with the aim to rule out malignancy.

\section{Discussion}

In the present study maximum number of patients (46.66\%) were found in the age group of 21-30 years. This was almost similar to the observation which was made by Navneet Kaur et al., ${ }^{[10]}$

The patients of BBDs generally present with one or more of these complaints - breast lump, breast pain or nipple discharge. In this study the most common presenting complain was breast lump $(63.80 \%)$ followed by lump and pain $(13.33 \%)$. Kulkarni et $\mathrm{al}^{[11]}$ observed lump as main presenting symptom in most of the benign proliferative breast lesion, which is in accordance with this study.

In the present study fibroadenoma was the most common breast lesion constituting $46.66 \%$ of benign breast lesions. Similar findings were reported by Amr et al, ${ }^{[12]}$ Kulkarni et al, ${ }^{[11]}$ Malik et al. ${ }^{[13]}$. In their study they found most common benign breast lump was fibroadenoma. Amr et al [12] reported $30.7 \%$, Kulkarni et $\mathrm{al}^{[11]} 62.32 \%$, Malik et $\mathrm{al}^{[13]} 41 \%$, cases of fibroadenoma. In present study the most common age of fibroadenoma was second and third decade which is comparable to the above studies.

In the present study fibroadenosis was the second most common benign breast lesion $29.52 \%$ and the maximum age incidence was observed in the age group of 21 to 30 years. Naveen et al., (2013) and Rashid et al., (2005) noted fibrocystic disease as the second common BBD after fibroadenoma accounting for $36 \%$ and $17 \%$ respectively. Stern (1992) found fibrocystic disease as the most common in females of all ages especially in the middle age group. ${ }^{[14],[15]}$. Amr et al ${ }^{[12]}$ reported maximum incidence of fibrocystic disease in 3135 years.

Acute breast abscess was also found in seven patients and five of these patients were lactating. However, no case of gangrene breast is found in our study as compared to the study done by Shukla and Kumar ${ }^{[16]}$ which reported two cases of 
breast abscess progressing to gangrene as a result of neglect. This is a positive sign as it indicates higher awareness of patients with respect to conditions of the breast.

Upper outer quadrant was the commonest site of distribution of lumps $(59.04 \%)$ when compared to the other quadrants. Decholonky T noted that 50\% of the lumps in his study were in this quadrant of the breast. ${ }^{[17]}$ Oluwole SF et al showed $60 \%$ of the lumps at this site. ${ }^{[18]}$

\section{Conclusion}

From the present study it is concluded that benign breast disease is most commonly seen in the age group of 21 to 30 years and majority of the patients present with breast lump followed by breast lump and pain. Fibroadenoma is the most common benign breast lesion encountered in clinical practice followed by fibroadenosis. Benign breast lesions are more common in the right breast and upper outer quadrant is mostly involved. Triple assessment provided a quick diagnosis and it alleviated unnecessary anxiety from the patients about breast cancer.

\section{References}

1. Shetty MK, Shah YP, Sharman RS. Prospective evaluation of the value of combined mammographic and sonographic assessment in patients with palpable abnormalities of the breast. Journal of Ultrasound in Medicine 2003;22(3):263268.

2. Moy L, Slanetz PJ, Moore R, Satija S, Yeh ED, McCarthy KA et al. Specificity of mammography and US in the evaluation of a palpable abnormality: retrospective review. Radiology 2002;225(1):176-181.

3. Soo MS, Rosen EL, Baker JA, Vo TT, Boyd BA. Negative predictive value of sonography with mammography in patients with palpable breast lesions. AJR American Journal of Roentgenology 2001;177(5):1167-1170.
4. Flobbe K, Bosch AM, Kessels AG, Beets GL, Nelemans PJ, von Meyenfeldt MF et al. The additional diagnostic value of ultrasonography in the diagnosis of breast cancer. Archives of Internal Medicine 2003;163(10):1194-1199.

5. Smith GE, Burrows P. Ultrasound diagnosis of fibroadenoma - is biopsy always necessary?[see comment]. Clinical Radiology 516;63(5):511-515.

6. Tamimi RM, Rosner B, Colditz GA. Evaluation of a breast cancer risk prediction model expanded to include category of prior benign breast disease lesion. Cancer. 2010;116:4944-53. doi: 10.1002/cncr. 25386.

7. Cote ML, Ruterbusch JJ, Alosh B, Bandyopadhyay S, Kim E, Albashiti B, et al. Benign breast disease and the risk of subsequent breast cancer in African American women. Cancer Prev Res (Phila) 2012;5:1375-80. doi: 10.1158/1940-6207.CAPR-12-0175.

8. Worsham MJ, Raju U, Lu M, Kapke A, Cheng J, Wolman SR. Multiplicity of benign breast lesions is a risk factor for progression to breast cancer. Clin Cancer Res. 2007;13:5474-9. doi: 10.1158/10780432.CCR-07-0928.

9. Aroner SA, Collins LC, Connolly JL, Colditz GA, Schnitt SJ, Rosner BA, et al. Radial scars and subsequent breast cancer risk: Results from the Nurses' Health Studies. Breast Cancer Res Treat. 2013;139:277-85. doi: 10.1007/s10549013-2535-9.

10. Kaur Navneet, Agarwal Nitin, Parwar Pankaj. Clinicopathologic profile of benign breast conditions in Indian women. Prospective study based on aberrations of normal development and involution classification. World J Surgery. 2012; 36:2252-58. [PubMed].

11. Kulkarni S, Vora I. M, Ghorpade K G, Shrivastava S: Histopathological spectrum 
of breast lesions with reference to uncommon cases. Obstet Gynecol India 2009; 59 (5):444-452.

12. Amr SS, Abdul Rahman, M Sadi, Fazalllahi, SS Sheikh. The Spectrum of Breast Diseases in Saudi Arab Females: A 26 yr Pathological Survey at Dhahran Health Center. Ann Saudi Med 1995; 15(2):125-132.

13. Malik MAN, Salahuddin O, Azhar M, Dilawar O, Irshad H, Sadia, Salahuddin A. Breast diseases; Spectrum in WahCantt; POF Hospital experience. Professional Med J Sep 2010; 17(3):366-372

14. Naveen N, Avijeet M and Vikrant M.A clinical study of benign breast disease in rural population. Journal of Evolution of Medical and Dental Sciences 2013; 12:5499-511.

15. Rashid R, Haq SM, Khan K, Jamal S, Khaliq $\mathrm{T}$ and Shah A.Benign breast disorders, a clinicopathological Study. Annals of Pakistan Institute of Medical Sciences 2005; 1:187-90.

16. Khanna S, Arya NC, Khanna NN. Spectrum of benign breast disease. Indian Journal of Surgery 1988; $50:$ 169-75.

17. Decholnoky T. Benign tumors of the breast. Arch Surg. 1937; 38:79.

18. Oluwole SF, Freeman HP. Analysis of benign breast disease lesions in blacks. Am J Surg. 1979;137:786- 9. 